\title{
Green Computing and Energy Consumption Issues in the Modern Age
}

\author{
Sonika Muriel Pinto ${ }^{1}$, Vemuri Divya ${ }^{2}, V_{\text {arsha }}{ }^{3}$, Nalina $^{4}$ \\ 1,2,3,4 (Information Science BMS College of Engineering,Bangalore, India)
}

\section{Abstract:}

Green computing is the environmentally responsible use of computers and their resources. Its main aim is to reduce carbon footprint and make efficient use of energy while also reducing toxic waste. Green computing aims at making effective and full use of computers and their resources and meeting the needs of the users while also sustaining the ability to meet future needs. Systematic analysis of energy consumption based on the type of service is done to determine efficient green computing methods to improve the complete energy consumption. In today's world, it is a major challenge to simultaneously build computers and other services that meet the ever increasing needs of customers and balance their performance to maximize energy efficiency and minimize e-waste production by using non-toxic materials for equipment manufacturing. By implementing the practices of green computing, we can reduce the use of resources and disposal of e-waste. There has been a steady increase in the use of computers and other electronic gadgets which means that the amount of electricity consumed has also been steadily increasing. This results in an increase in $\mathrm{CO}_{2}$ in the atmosphere. In this paper, we will look into the details of green computing such as its theories and designs, along with its heat and energy consumption issues. This paper will help us to take a few activities that are at present time under the field on computers/electronics and better approaches to save huge quantities of energy which is wasted in a large manner.

Keywords - green computing, carbon reduction, efficient computing, sustainable development.

\section{INTRODUCTION}

Green computing is the study and practice of using computers and their resources in an environmentally responsible and ecofriendly manner. It is designing, planning, engineering, manufacturing, using and disposing of electronic devices in a way that reduces their environmental impact. Green computing is used to make environment more sustainable. The main aim of green computing is to improve environmental condition by efficient use of energy. Manufacturing equipment that are energy efficient, minimizing e-waste and using nontoxic materials and chemicals during manufacturing helps in reducing the impact over the environment.

The number of computers, servers and other electronic devices are increasing day by day. This is leading to the increase of electricity consumption. Since electricity is produced by burning coal and other fossil fuels, the amount of carbon dioxide and other greenhouse gases are increasing in the atmosphere. Greenhouse gases help in maintaining the temperature. If the amount of greenhouse gases in the atmosphere increases, more heat is trapped in the atmosphere which leads to global warming. The toxic materials and chemicals used in manufacturing the electronic devices and ewastes are also polluting the atmosphere. Air, water, food and soil which affect our daily life are getting polluted. The data centers use a large amount of power and release a lot of heat and gases. AC's, Refrigerators, UPS and computers take a large amount of energy and evolve heat and gases. These gases are very harmful for our lives. It has been observed that $\mathrm{AC}$ and refrigerators release $\mathrm{CFC}$ type gases, which contributes to global warming. This in turn leads to diseases such as different types of cancers, asthma, etc. Global warming also leads to floods, melting of glaciers, drought and increase in the temperature of the earth.

Many companies are coming forward to try and solve these problems and make environment sustainable. They are trying to manufacture devices whose consumption and release of energy is low. Though most of the manufacturing units are 
able to successfully manufacture the desired devices which are more efficient and accurate, the amount of energy consumption and the amount of toxic, dangerous gases and chemicals released are contributing to the environmental pollution. Industries use chemicals such as mercury, lead, cadmium and other toxic chemicals which are the main sources of pollution. A research conducted estimated that the computers and electronic devices are responsible for two-fifth of lead in land-fills on the earth. By using green computing resource, consumption and disposal of e-waste can be reduced.

\section{LITERATURE SURVEY}

Priya Rana [1] focuses on the overview of the concept of green computing and how we, as normal people can strive towards a sustainable environment. Green computing is the environmentally responsible use of computers and related resources with the main aim of reducing or minimizing carbon footprint. It centers on energy efficiency, reducing resource consumption and the disposal of e-waste in a responsible manner. The paper emphasizes on the importance of utilizing green computing techniques and goes on to talk about the various ways in which green computing can be adopted in our day to day life.

Meenakshi Gupta et al [2] look into not only the end products on the desk but the entire life cycle of computer and what techniques can be implemented in these various stages such as manufacturing, production, etc that are green initiatives. Due to the growing dangers of high energy consumptions, e-waste productions and pollution, it's not only the government agencies but also private firms worldwide that are implementing more environment friendly computers. Understanding the life cycle of a computer is essential to attain a green, sustainable environment. The paper focuses on the different approaches that can be adopted to make computers green, from beginning to end. When various major players like the businesses, consumers, governments, firms take up the green approach, it is possible to ensure that the green computers in the future are more energy efficient, with less carbon footprint and recyclable and biodegradable.

Suman et al [3] analyses the history of green computing, the need for green computing, methods to be adopted and the future of green computing. In recent years, companies in the computer industry have come to realize that adopting greener methods is in their best interest, both in terms of public relations and reduced costs. IT department is usually always the one department that uses the most amount of power which in turn is an excessive amount of overhead for a business as well as a source for toxic waste. Green computing involves minimizing wastage of any sort (electricity, computer resources, etc) whenever possible and also maximizing efficiency. One of the first initiatives was done in the Unites States where Energy Star program by the EPA (Environment Protection Agency) was proposed to promote energy efficiency in hardware. This initiative is now widely used all over the world. Similarly, there have been numerous programs to help practice green computing. As for the future of green computing, sue to the rapid growth in technology, it is possible to manufacture more environmental friendly computers and accessories such as recyclable laptops, laptops that run on solar cells, EVO PC that's made of materials that are sustainable and reduces carbon footprint, etc.

Fatima Shakeel1 et al [4] focus on energy efficiency of data centers and virtualization of servers. The increase in the consumption of power and energy which releases the greenhouse gases like carbon dioxide has caused an impact in the performance. The demand for performance improvement is always increasing. With the increase in the usage of cloud computing more and more data centers are being set up which consumes a lot of energy and power. There is a need to optimize the power consumption in such systems. Optimization of physical data centers is one such method. Anton Beloglazov proposed a scalable, effective and decentralized algorithm for the resource allocation that reduces the power consumption. Consolidation of virtual machines has great effect on the power savings. Because most of the power consumption of data centers is due the multimedia services, it can be optimized by using various techniques like network aware transmissions, shared memory servers, processing unit etc.

Omar S. Saleh et al [5] talks about how databases, servers, datacenters can be effectively used such that the amount of greenhouse gases released is minimized. Virtualization is used to merge resources to work together as a single resource. This creates a highly efficient environment. Writing an optimized query is another way to go green. This paper also talks about data mining and its impact on health care. Data mining helps in preventing errors, discovering new useful and potentially life-saving information. There are several models in data mining. The model that fits the problem has to be chosen for efficient use of energy. Server virtualization, power monitoring software and cloud computing are recent trends in green computing. Green database, data mining and data warehousing would be an appropriate choice for the healthcare system due to their characteristics. Thus changes in infrastructure, optimization techniques and virtualization techniques are used to reduce the amount of greenhouse gas emission which helps in creating a sustainable environment.

Mydhili K Nair et al [6] focuses on software as a service in green computing. Software as a Service is a model used by service providers to provide internet hosted version of their application. The most common implementation of SaaS is web Service. Using SaaS we can reduce the number of applications deployed on the servers by using the similar applications 
hosted by the SaaS providers. This helps in reducing the storage space and computational power required by the data centers, thus aligning the $\mathrm{SaaS}$ architecture to green computing. Generic web service is a web service which supports many functions and this helps in orientation towards green computing. Using SaaS helps in saving money and time, focusing on the business needs rather than deployment, gain immediate access to updates in software. Optimization of SaaS design by adopting generic web services helps in saving energy by reducing storage, computational and processing power at the servers.

Chia-Tien Dan Lo et al [7] talks about inculcating green computing in algorithms and operating systems. There are several facets to achieve green computing like designing, manufacturing, using, and disposing computer components including hardware and software. IBM's "Project Big Green" is energy efficient and saves $42 \%$ of power. This paper talks about very little effort has been made on fine grained green computing for computer architecture, embedded systems, operating system, programming, computer networks and algorithms. Usually performance of algorithms is analyzed on the basis of time and space, but very few concentrate on how much energy is consumed. The next generation computer scientist have to focus on how to compromise a design that will maximize the overall performance subject to multiple design dimensions.

\section{A. Main Problems and concerns}

Today, almost all streams from IT to medicine to transportation and agriculture use machines which directly or indirectly require large amounts of power and money for its effective functioning. Computers play a vital role in our lives and yet, despite having good qualities it takes a lot of energy to manufacture and package computers, store and move data from one place to other, etc. Humans are dangerously dependent on computers and other electronic gadgets and sometimes don't realize the level of damage these devices cause to the environment. With the ever changing technology, computers also change and when new computers are brought in, the old ones are dumped in landfills. This results in major issues and pollution. Computer manufacturing companies use materials like lead, mercury, cadmium and other toxic materials. Due to this reason, it is important to incorporate green computing. Rather than giving importance to just speed, price and cost, it is also important to focus on achieving energy efficiency and to use less toxic materials and this is where green computing comes in. Data centers are another area that requires green computing as they generate large amounts of heat and consume huge amounts of electricity. Many companies are adapting alternative, eco-friendly methods and technologies to maintain data centers.

\section{B. Green Computing and its Benefits}

Green Computing has turned into an ingenious route on how innovation and environment converge together. Green computing is fundamentally the efficient use of computers and its resources. It is also known as Green IT. The key focus in Green IT is efficiency in computing and promoting environmentally friendly computer technology. Green IT starts at the basic level of designing and manufacturing computers and it can be implemented throughout a computer's life cycle including reuse, recycle and disposal.

The benefits of Green computing might not be much when taking only one computer into perspective but it can have a huge positive impact on the environment when it's adapted on a large scale basis. The advantages of green computing are extensive, not just from simply the buyer, or business, or country's point of view but it is a global advantage. Green computing decreases energy demands, waste, and money of how we utilize technology which unequivocally impacts nature, and our expenses.

\section{Existing System}

\section{Energy Star Program}

In 1992, America introduced the energy star program wherein the main aim was to reward computing/electronic products that provided maximum efficiency with minimum energy consumption. Under this practice, energy star labels are rewarded to homes that have been individually tested to be at least $15 \%$ more efficient than the standard directed by the relevant state or local energy codes in a given area. These energy star labels can be given to televisions, refrigerators, computers, air-conditioner, etc.

\section{EPEAT (Electronic Products Environmental Assessment} Tool):

It is another environmental rating tool that checks the product's standard. All products which are registered are made better to protect human health and these items can be easily upgraded and recycled. These products have reduced the percentage of lead, mercury and cadmium. These products are more efficient in energy and reduce the environmental impact.

\section{Virtualization:}

Virtualization is a technique that is growing in the IT industry. It is a cast saving, energy reducing technique that allows multiple operating systems/multiple applications to run 'virtually' on one physical server or desktop pc. Virtualization goes hand in hand with green computing as both result in decreased energy use, reduction in toxic waste (since less physical hardware is used to support more virtualized software) and also reduction in facility requirement as equipment reduction leads to more space for business to increase without the need for a bigger data center

Green data centers: 
Data centers are essentially warehouses that contain computer systems and its components such as servers and other storage systems. Data centers are crucial when it comes to IT companies or any other establishments that deals with data and communication. It centralizes an establishment's IT operations and equipment, as well as where it stores, categorizes and distributes data. Due to the nature of data centers, they emit large amounts of heat and $\mathrm{CO} 2$ frequently and turning it down can result in loss of vital information during data transfer. They need to maintain around the clock and should be away from the everyday public and hence monitored round the clock. Data centers thereby not only have a huge negative impact on the environment due to their high consumptions of electricity and emission of $\mathrm{CO} 2$, they also are cost and time effective due to their high maintenance. Due to these reasons, companies have started to make their data centers green in order to reduce its environmental impact and at the same time, make it efficient. The building and operation of a green data center includes innovative technologies and policies. It includes:

1. Sustainable landscaping

2. Waste recycling

3. The use of low-emission building materials, carpets and paint.

4. Minimizing carbon footprint

5. The use of alternate energy efficient technologies such as heat pumps, evaporative cooling and photovoltaic cells.

6. The use of electric company vehicles.

The process of building and certifying a green data center is expensive but is cost saving in the long run. Another major advantage of green data centers is that they offer a healthy, safe and comfortable work environment to their employees.

Solar Energy Computing:

Solar energy is one of the most popular and commonly used renewable sources of energy. It's abundant, clean and apart from the initial rate of installation, it is also cheap. So it makes sense that it has been used to power PCs and other electronic gadgets. Solar energy is used in the place of electricity that decreases the consumption of electricity and hence it promotes sustainable development of the environment. Solar powered computers require solar panels that contain solar cells that trap the heat of the sun and convert it into energy. This is then used to power up a wide variety of devices including computers and even supercomputers.

\section{Carbon-free computing:}

There has been an increase in the consumption of electricity by the IT sector. It is estimated that around 10 percent of the electricity goes towards powering the entire IT ecosystem which includes data centers, communication networks, manufacturing and use of the computers and other connected devices. There are many companies like Google, Hewlett
Packard etc are purchasing clean energy which involves solar and wind energy. But the challenge is that this renewable energy is intermittent, it requires large footprint, and also the batteries. Therefore, the path to carbon free data centers seems quite unclear for the companies. Some companies have tried to change their design and operation but it does not prove to be very efficient at the production rate. The solution to achieve a renewable energy efficiently is by combining the technology with hydrogen production and storage. Hydrogen fuels are the heart of this strategy. These hydrogen fuels generate energy through the electrochemical reaction between air and hydrogen. This generated energy can be stored in batteries or can be directly used to run an electric motor. Automotive manufacturers like Daimler have been successfully testing fuel cells in cars for many years. The advantage of using hydrogen fuels over traditional fossil fuels is that the only by-product is water. It means that the data centers no longer have to rely on the generators powered by fossil fuels or other carbon-heavy backup power sources. And also hydrogen fuel cells can run for as long as there is hydrogen to fuel it and there is no limit to the amount of power generated.

\section{Data Centers}

Green data centers are computing facilities for enterprise that is managed, built and operated on green computing principles. The features and capabilities remain the same, but the energy consumption and space is reduced also the operation and design are environment friendly. In the August of 2007, a report was published by Environmental Protection Agency (EPA) on "Data Centers and Server Energy Efficiency". In this report the dramatic growth in energy costs of data centers and the rapid increase in data center power consumption were detailed. A new Energy Star benchmark for data centers was implemented by Energy Protection Agency. After this publication, major IT manufacturers started going green and developing "Green initiatives and products. With so many competing and major manufactures having developed energy efficient products, the prudent approach is to compare competing technologies and evaluate the energy consumption.

The geothermal and hydroelectric powered 'Verne Global' is the first zero carbon data center. It deals with High Performance Computing applications. Since the High Performance Computing application put heavy load on servers, plenty of electricity is required to not only for transactions but also for keeping the infrastructure cool. The techniques used are crash simulations and aerodynamic calculations. Facebook's data centers are located in Arctic Circle and use Chilly Nordic air and traditional water cooling techniques to keep from overheating. The hydroelectricity generated locally is so reliable, that Facebook has been able to reduce the number of backup generators. The server hardware is based on Open Compute project designs. Apple has also gone green by powering its facilities with renewable solar, wind, hydro and geothermal energies. It includes chilled water energy storage systems along with free outside air cooling. High efficiency LED lighting is teamed with motion sensors. 
Google's data center in Hamina, Finland uses natural sea water for cooling and not chemicals. The company also recycles 100 percentage of electronic equipment that it replaces.

Modular green data center is a system consisting of engineered modules and components to offer scalable performance and data center capacity with cooling and power options in such a way that the energy consumption is less. Modular green data centers consists of Server Rack, HVDC Battery, HVDC power unit, I/O board, DC distribution board, Liquid cooling pump unit, Cooling tower and a Fresh air intake unit. Some of the features of Modular green data centers are

1. Heat removal by liquid cooled fan-less server and air conditioner-less data center with fresh intake unit.

2. DC power supply and adaptive power control.

3. Energy saving operation of server.

Before you begin to format your paper, first write and save the content as a separate text file. Complete all content and organizational editing before formatting. Please note sections A-D below for more information on proofreading, spelling and grammar.

Keep your text and graphic files separate until after the text has been formatted and styled. Do not use hard tabs, and limit use of hard returns to only one return at the end of a paragraph. Do not add any kind of pagination anywhere in the paper. Do not number text heads-the template will do that for you.

\section{E. Conclusion}

Green computing methods and issues which were discussed in this paper help in reducing power consumption and heat which is evolved during processing. Power consumption in computer can be managed in various ways. There are a lot of techniques in green computing which are more efficient and advantageous and which can be discovered in this age of rapid development. Always, the problem is balancing the growing demand of technology and maintaining a sustainable environment. By using the methods mentioned in this paper we can save energy, emission of $\mathrm{CO} 2$, toxic materials and promote a sustainable environment while simultaneously not compromising much on the demand for technology.

\section{REFERENCES}

[1] Priya Rana, "Green Computing saves Green” Department of Information Technology, RKGIT, Ghaziabad International Journal of Advanced Computer and Mathematical Sciences Vol1,issue, Dec,2010,pp45-51

[2] Meenakshi Gupta and Garima Gupta, "Green Computing - A Step towards Better Milieu", Journal of Engineering, Computers \& Applied Sciences (JEC\&AS), Volume 2, No.9, September 2013.

[3] Suman, Soniya and Mehak, "A Greener Approach to Computing", International Journal of Advanced Research in Computer Science and Software Engineering in Volume 2, Issue 2, February 2012

[4] Fatima Shakeel and Seema Sharma, "Green Cloud Computing: A review on Efficiency of Data Centres and Virtualization of Servers", 2017 International Conference on Computing, Communication and Automation (ICCCA)

[5] Omar. S Saleh, H Muhammad, Samar \& K Farhan, Marwah K Farhan, "The impact of Green Database, Data Mining and Data Warehousing on the HealthCare System", International Journal of Advanced Research in Computer Science and Software Engineering (2014).

[6] Mydhili K. Nair and Dr. V. Gopalakrishna, "Generic Web Services: A Step towards Green Computing", International Journal on Computer Science and Engineering, Vol. 1, No. 3, pp. 248-253, 2009.

[7] Chia-Tien Dan and K.Qian, "Green Computing Methodology for Next Generation Computing Scientists", IEEE 34 ${ }^{\text {th }}$ Annual Computer Software and Applications Conference (COMPSAC) (2010), pp. 250251 